\title{
A Review Paper on 5G Wireless Technology
}

\author{
Suman Sharma ${ }^{1}$, Richa Sharma ${ }^{1}$, Kriti Sharma ${ }^{2}$ \\ ${ }^{1}$ Department of Electronics and Communication Engineering, Swami Keshvanand Institute of Technology, \\ Management \& Gramothan, Jaipur, Rajasthan (INDIA) \\ ${ }^{2}$ Deptt. of IT, ACEIT, (RTU), Jaipur (INDIA)
}

Email: suman.sharma.csit@skit.ac.in, sharmaricha670@gmail.com, kriti4u39@gmail.com

Received 12.02.2021, Received in revised form 19.03.2021, Accepted 29.03.2021

\begin{abstract}
The in-depth exploration in the era of fifth generation (5G) witreless network technology is a sign of technical revolution to joint up with the demands and requirements for very fast speed communication and applications which are based on Internet of Thing (IoT) as well. IoT devices and the mobile phone technology supports the 5G technology to invent with distinct facilities like the smart city, smart building and many more that will need an antenna with 5th Generation technology, with reduced latency, minimum path loss and steady pattern of radiation. This paper provides a deep study of various characteristics of all the wireless generations with their salient characteristics along with 5G technology.
\end{abstract}

Keywords-5G technology, Internet of Thing (IoT), latency, low path loss, radiation pattern Introduction.

\section{INTRODUCTION}

The entire world has witnessed a number of developments in the field of Communication. In the last few years, drastic development of wireless services and technologies has contributed a lot in forming our economic system and society. The world has turned towards digitized format, from services that are using voice only applications to wireless broadband connectivity, from second Generation to fourth Geneartion and even after this also [1]. New development in technology not only supports but also extends the limits of easy to use policies giving authorization to a number of users and uses. It is correct in view of fifth Generation technologies which permits larger bands of spectrum for quality purposes than many previous wireless generations.

The next offered main phase of mobile phone telecommunication standards in the Fifth Generation wireless networktechnology are beyond the present Fourth Generation/IMT Advanced standards. Along with a number of improvements $5 \mathrm{G}$ planning carries The speed of Internet connectivity is very fast as compared to current $4 \mathrm{G}$.

The Fifth Generation smartphone mixed media networks of internet can be entirely communicated wirelessly without any major constraints that creates a complete real world wirelessly known as World Wide Wireless Web (WWW). It is based on $4 \mathrm{G}$ technologies.

\section{THE EVOLUTION OF GENERATIONS FROM 0 TO $5^{\mathrm{TH}}$ GENERATION}

OG WIRELESS SYSTEM: In the late of year 1940, the first ever radio telephone service came into picture. It was created for communicating between the callers in four wheelers to the land-line connected telephone network.

During the year 1960's, the new technology called Improved Mobile Telephone Service (IMTS) which was a system started by Bell Systems brought some of the changes like Direct Dialing and a large bandwidth. In the late1960's and early 1970's, IMTS was the main technology on which the very first analog systems were based upon.[2]

$1 G$ WIRELESS SYSTEM: These system usesnetworks analogy signals. A very high frequency which is near to approximately $150 \mathrm{MHz}$ was used for voice modulation.

Analog cell phones of 1 st generation which are having a speed limited up to $2.4 \mathrm{kbps}$, allow the callers to initiate voice calls in one country. The salient features of $1 \mathrm{G}$ standard are:

* Advanced Mobile Phone System referred as AMPS

*Nordic Mobile Telephone referred as NMT [2].

2G WIRELESS SYSTEM: These wireless systems are commercially launched on the standards of GSM (1991). 30 to $200 \mathrm{KHz}$ is the bandwidth used by $2 \mathrm{G}$ Wireless system. 2G networks allows for a lot more penetration intensity. E.g. GPRS, CDMA[2].

It also provides the facility of SMS (Short Message Service).

3G WIRELESS SYSTEM: These type of wireless system makes use of technology of Code Division Multiple Access and Time Division Multiple Access. In computer networking and mobile devices area $3 \mathrm{G}$ came into the use (WCDMA, WLAN and Bluetooth) (cell phone and GPS) in 2005. In terms of spectral efficiency, $3 \mathrm{G}$ technology is far better than $2 \mathrm{G}$ technology. Transmission speed is from $125 \mathrm{kbps}$ to $2 \mathrm{Mbps}$. Packet switching is the main technology through whichData is sent. The main feature of $3 \mathrm{G}$ Wireless systems is very high clarity in Voice calls and Access to Global Roaming[2]. 
4G WIRELESS SYSTEM: These type of wireless systems should be able to provide a smooth worldwide roaming with $4 \mathrm{G}$ Mobile Phones. 4G provides both the cellular and multimedia services everywhere in the world. Nowadays with $4 \mathrm{G}$, the mobile TV provider redirects or gives the facility of TV channel directly and completely to the subscriber's phone where it can be watched. One of the main featuresof 4G Technology is Video on demand on the subscriber's phone. Video conferencing facility allows subscribers to watch and communicate with each other. Using telecommunication, one can also have medical advice. Salient features like Mobile ultra-broadband (gigabit speed) access and also good multi-carrier transmission [2] is also available in $4 \mathrm{G}$ wireless systems.

4G provides few same features as Third Generation along with some important applications like MultiMedia Newspapers, enables users to watch T.V programs with good visually and clarity and send Data with a lot more high speed than the other previous generations [3]

5G WIRELESS SYSTEM: Huge consortiums of much more significant worldwide telecommunication are progressing to create universal values across Fifth generation wireless network technology. Despite a lot of these standards don't get hardened, experts of this field yet anticipate it to be more suited with Fourth Generation and third Generation. With the increase in growth of demand of the users and callers exponentially, Fourth Generation wireless technology can be easily substituted with Fifth Generation technology with a new advanced access technology named as Beam Division Multiple Access i.e. BDMA and or Filter Bank multi carrier abbreviated as FBMC multiple access. By considering the matter of the base station which is having communication with the mobile stations, there lies the main concept behind BDMA technique. An orthogonal beam is given to each and and every mobile station and by using Beam Division Multiple Access technique one can divide that antenna beam according to locations of the mobile stations for openhanded multiple accesses to the mobile stations, that will definitely increase the competency of the $5 \mathrm{G}$ system and thus this is observed as the important and main process of BDMA communication.

Few of the reasons to turnin the direction of $5 \mathrm{G}$ wireless systems are based on the present scenarios. The hindrances that are not looked upon in $4 \mathrm{G}$ technology can be tackled by $5 \mathrm{G}$ cellular networks perfectly. These are

1: Higher capacity

2: Larger data rate

3: Lowered cost

4: Consistent Quality
5: End to End latency has been lowered, 6: connectivity to the massive device,

\section{SALIENT FEATURES OF 5G}

- $5 \mathrm{G}$ wireless technology offers the increased resolution for intensemobile phone on daily basis and gives user'sgood and better connectivity to Internet.

- Billing limits in advance are provided by $5 \mathrm{G}$ technology that is why this technology will be more successful in the modern era.

- 5G technology provides mobile phone users, mobile records easily available for better printingtasks.

- $5 \mathrm{G}$ wireless technology allows for huge volume data spread in Gigabits.

- More accurate and reliable results are obtained by the information that is provided from the data transfer by $5 \mathrm{G}$ technology.

- Applying technology named as remote control one can getan easy and comfortable $5 \mathrm{G}$ access in less time.

- Virtual and particularwireless networkis also supported by $5 \mathrm{G}$ technology

- 5G Technology provides a faster upload and data download speed as compared to previous generations.

- The 5G wireless technology provides a betterinternet connectivity all around the world.

- Wireless technology of 5G network is authentic and high speed [4].

\section{5G MERITS AND DEMERITS}

\subsection{Merits of 5G Technology}

There are a number ofmerits of $5 \mathrm{G}$ technology as listed below

- Excessive resolution and two directionhuge bandwidth [8].

- $5 \mathrm{G}$ wireless network Technology has the ability to collect all wireless networks on a single platform.

- $5 \mathrm{G}$ Technology is highly efficient than other counterpart technologies.

- $5 \mathrm{G}$ wireless network will ease the subscriber supervision methods for the fasteractivity.

- This technology will offer a vast broadcasting data in the units of Gigabit that will help 60,000 plusconnections.

- Compatible with the earlier wirelessgenerations.

- $5 \mathrm{G}$ network is highly sound to provide support to heterogeneous resources (including private network) technologically.

- Possible to offer constant, uninterrupted, and continuousinternet connectivity worldwide [9].

- 5G technology very well supports Artificial Intelligence applications [10]. 


\subsection{G Demerits}

Though, 5G wireless network technology is exploredand its concepts are there to resolve the existing radio frequency based transmissionissues and major hardships of cell phone world, still due to some of the security reasons and need of technological enhancement in majority of the geographical regions, it has underlyingdemerits

- The research on viability of 5G Technology is currently ongoing.

- The internet accessing speed of 5Gwireless network technology is still difficult to attain in nearby future, due to the inefficient technological network support worldwide.

- A large number of the earlier used devices will be inefficient to $5 \mathrm{G}$ technology, hence, each one of them will be required to be exchanged with newer versions.

- Huge amount ofcost is required to develop infrastructure needs.

- 5G wireless network technology needs to address the issues related to security and data privacy.

\section{REFERENCES}

[1] AleksandarTudzarov and Toni Janevski, "Functional Architecture for "5G Mobile Networks" International Journal of Advanced Science and Technology,July (2011). Volume. 32, Pages 82-85.

[2] A Review Paper on 5G Wireless Technology, Journal of
Instrumentation and Innovation Sciences,Volume3, Issue 2,MAT journals..

[3] Akhilesh Kumar Pachauri, Ompal Singh, "5G Technology Redefining wireless Communication in upcoming years" by International Journal of Computer Science and Management Research Aug (2012) Volume 1 Issue 1 ISSN 2278 733X.K.

[4] Meenal G. Kachhavay, Ajay P. Thakare, "5G TechnologyEvolution and Revolution" International Journal of Computer Science and Mobile Computing, March(2014).Volume 3 Issue.3,Pg. no. 1-4.

[5] Anwar M. Mousa "Prospective of Fifth Generation Mobile Communications" International Journal of Next-Generation Networks (IJNGN),September (2012),Volume 4, No.3,Pg no. 94-97.

[6] Akhil Gupta, Rakesh Kumar Jha "A Survey of 5G Network: Architecture and Emerging Technologies" IEEE Letters,(2015), 2169-3536 (c)

[7] Rakesh Kumar Singh , Deepika Bisht and R.C. Prasad, "Development of 5G Mobile Network Technology and Its Architecture" International Journal of Recent trends in engineering and Research, (2017), Volume-3, issue -10, pp: 196-201.

[8] Jivesh Govil, Jivika Govil, "5G: Functionalities development and an Analysis of Mobile Wireless Grid", First International Conference on Emerging Trends in Engineering and Technology.

[9] VWS Wong, LC Wang "Key Technologies for 5G Wireless Systems", (2017).

[10] Yejian Chen; Mark Doll, "Enhanced Control Signal and Data Detection for $5 \mathrm{G}$ Multicarrier Low Power Communications", IEEE 84th Vehicular technology Conference (VTCFall), (2016), Pages: 1-5. 